\title{
Legal Regulation of the Quality and Safety of Food Products: Analysis of the Current State in the Context of Ensuring National Security of Russia
}

\author{
Vorontsova E.V. \\ Department of Financial Law, Constitutional, Civil and \\ Administrative Procedure \\ South-West State University \\ Kursk, Russia \\ proskyrinae@mail.ru
}

\author{
Vorontsov A.L. \\ Department of Administrative and Labor Law \\ South-West State University \\ Kursk, Russia \\ vorontsov.a.1@mail.ru
}

\begin{abstract}
The article is devoted to the analysis of the current state of the organizational and legal mechanism for ensuring the quality and safety of food products. Ensuring the quality and safety of food products is an urgent task of the Russian state, the solution of which depends on ensuring the country's national security. Noting the importance of the qualitative characteristics of food products for the realization of such national interests as improving the quality of life, strengthening the health of the population, ensuring stable demographic development of the country, the authors draw attention to the underestimation of this factor by the Russian legislator in terms of ensuring national security. Recognizing that the decline in the quality of consumer goods is a threat to national interests, the legislator, however, does not attach the issue of ensuring the quality and safety of food products of independent significance, preferring to solve it within the framework of more general tasks.In the National Security Strategy of the Russian Federation, the task of ensuring the quality and safety of food products is not recognized as a strategic national priority, which significantly limits the legal and organizational capabilities to solve this problem.

In addition, imperfect legal regulation of food production and turnover creates significant difficulties. The regulatory framework in this area does not allow building an effective food quality management system, which necessity is dictated by the needs of ensuring Russia's national security. Improving the organizational and legal mechanisms for ensuring the quality and safety of food products is possible by harmonizing the requirements for their quality and safety, which involves changing the current system of technical regulation based on the predominant guarantee of product safety indicators to the detriment of its quality.
\end{abstract}

Keywords: quality and safety of food products, national security, national interests, organizational and legal mechanism, food security, legislation, legal regulation

\section{INTRODUCTION}

The undoubted successes of the past two decades, achieved by our country in the economic, political and military spheres, don't remove urgent issues related to ensuring its national security. Moreover, the current situation of open geopolitical confrontation (which, apparently, is gaining a long-term character) makes us pay attention to a number of factors that were not previously given priority, but which did not become less important in the life support system of society. One of such factors is the quality and safety of food consumed by the population.

The influence of this factor on the quality of life and prospects for the development of society is now increasingly obvious. The pandemic of endocrine, oncological and other diseases that engulfed the world, and which were largely a consequence of the consumption of low-quality, and often unsafe food, is a clear confirmation of this.

In Russia, the problem of the quality and safety of food products has long remained «in the shadow» of the problem of providing the population with food. In conditions of total deficit, this problem objectively came to the fore, and ensuring the necessary amounts of food in the food market was the main task. With the solution to the problem of food shortages, it became possible to address issues of ensuring the quality and safety of food products, especially since the negative consequences of inattention to these issues began to manifest themselves quite acutely.

The Russian state has become faced with the need to create a holistic mechanism to satisfy the objectively significant needs of the population in high-quality and safe food. Legal regulation of the production and turnover of food products plays a fundamental role in this mechanism, since right, as practice has shown, is the most effective tool to ensure the 
quality and safety of goods. In turn, the sphere of legal regulation of the quality and safety of food products is not without drawbacks, some of which will be analyzed in the article.

\section{Methodology}

The authors' study was based on the general principles of scientificness, objectivity, and the dialectical relationship of the phenomena studied. The features of the subject under study, consisting in its poorly understood, problematic nature and versatility, determined the specifics of the methods used, which were the methods of logical justification and analysis, comparative legal and retrospective methods, the problem statement method, the formal legal method.

\section{LITERATURE REVIEW}

Despite the almost complete absence of works analyzing the problems of quality and safety of food products directly in the context of ensuring national security, a number of aspects of this multifaceted topic have been reflected in studies in other scientific areas and specialties. The results of these works allowed us to more fully present the spectrum of problems arising in this area, and in some cases served as a methodological basis for studying the problems of quality and safety of food products in the aspect of our study.

Despite the fact that most of the works devoted to ensuring the quality and safety of food products are devoted to the technological component of this process, nevertheless, in recent years, a lot of works have appeared that analyze the issues of legal ensuring the quality and safety of food products. Of interest are the works of M.T. Nurgaliyeva, A.K. Smagulov, Zh.A. Iskakova [1], E.V. Tsaregorodtseva [2], O.V. Arnautov [3], containing a comparative legal analysis of modern mechanisms for ensuring the quality and safety of food products in Russia and other countries. In addition, the problem of legal regulation of this sphere was also analyzed in the aspect of regional rule-making - in the work of A.Yu. Mokhov [4].

Noteworthy are the works of Belova L.V., Pilkova T.Yu., Fedotova I.M. [5], Shaurinoy O.S., Gorbatova A.V. [6] analyzing issues of food quality and safety in terms of protecting consumer health and ensuring food security.

A large number of studies on the issue of quality and safety are devoted to organizational, managerial and economic aspects of this problem. These include the work of Andreev S.P. [7], Astafieva V.V., Vasilyeva O.K., Zernina S.G. [8] and etc.

\section{RESULTS AND DisCUSSION}

Most of us perceive the quality and safety of food products as a problem that lies in the plane of answers to the following questions: is it possible to eat this or that product, or is it impossible because of the threat to life and health in this case (when it comes to safety product); and how tasty and healthy the product is (when it comes to its quality). In general, this approach can be recognized as correct, since it in the most general form reflects the objective human needs for food.
However, the perception of the quality and safety of food products exclusively from the perspective of the above issues is, in our opinion, very simplified, since it does not reflect the entire spectrum of threats arising in this area. But there really are threats, and their number in recent decades has increased significantly as a result of a significant increase in the volume and species diversity of food products, the use of the latest achievements of science and technology and other factors in its production.

It would seem that the expansion of the food product line, including through the latest technologies, is of extremely positive importance, since it is aimed at increasingly satisfying consumer demand, which in turn reflects human needs in the food sector. At the same time, we sometimes forget that demand itself, needs themselves in modern conditions can be easily formed from the outside that is, artificially - through advertising, manipulating public opinion and other ways of exerting an information impact. A clear confirmation of this is the practice of modern marketing with its systems of price discounts, sales, technologies for introducing certain food stereotypes into the public consciousness, etc.

As a result, in full accordance with the laws of Hegelian dialectics, the advantages of the development of the food industry, including the food consumption system, smoothly pass into its disadvantages, which turn into the emergence of obvious and hidden threats to public health. Moreover, latent (delayed) threats associated with the quality and safety of food consumed by the population represent almost more danger to society than obvious threats, which, due to their obviousness, cause an effective reaction from the state and, as a rule, are quickly eliminated. The implicit nature of latent (delayed) threats allows the problem to develop, often to the point where even the toughest government measures may not have the desired effect due to the irreversibility of many physiological consequences associated with nutrition.

The above reasoning is based on data from medical science. For example, it has long been proven that a lack of animal proteins and fats, the main sources of energy in the human body, leads to a decrease in muscle mass and growth. At the same time, their excess in food contributes to the growth of cardiovascular diseases, which directly affects the life expectancy and labor activity of the population. Excessive use of salt leads to the same consequences, although salt is a source of essential trace elements and is also the most common preservative. Thyroid disease can be triggered by a lack of iodine in foods. In addition, such a banal reason can make us less «smart,» since a lack of iodine in the body directly affects our cognitive abilities. According to some scientists, in some cases even human behavioral reactions may depend on the nutrition structure [9]. Very significant, but not yet fully understood risks can be created by food products obtained using genetic modification technologies (according to some reports, they can affect the human genome) [10].

Thus, the knowledge at our disposal allows us to conclude that the problem of the quality and safety of food products is not only a problem of the comfort of our existence, but also a problem that largely determines the development opportunities 
of our society in the near and distant future, taking into account its impact on the quality of human potential.

In this regard, it is not difficult to assume that in the context of the policy of «containing Russia» pursued by some countries, the long-proven technologies of forming food addictions of the population can be used by our geopolitical rivals as a tool to weaken our country. Hence, the problem of the quality and safety of food products acquires a completely different meaning than the one in which it is usually considered in legal science, i.e. as a problem of the realization of certain rights, improvement of the sectorial regulatory mechanism, etc. The problem of the quality and safety of food products is becoming a factor that directly affects the national security of the Russian Federation. Awareness of this circumstance compels a different attitude to the need for the earliest possible construction of an effective quality management system for food products as a system that guarantees the maintenance of public interests in the field of food consumption.

It cannot be said that Russia has no experience in this matter. In the Soviet period (it is also called the period of the planned economy), the quality and safety of food products was regulated, like any other, by a system of GOSTs (state quality standards), which stipulate the criteria that a particular type of product should meet. However, such a system of legal regulation of production and turnover of food products was quite suitable only in the conditions of a «closed» economy, focused on the domestic market and on the inexperienced consumer, who often did not have the opportunity to choose a product. The economic transformations that created a competitive environment and opened up the Russian food market to foreign manufacturers fundamentally changed the conditions for the functioning of the food market, which made the GOST system ineffective and entailed its actual abolition.

However, the conditions of the free market create additional difficulties for the system to ensure the quality and safety of food products, which the Russian legal system cannot yet overcome, which impedes the maintenance of the national interests of the Russian Federation.

It should be remembered that for the organizational and legal solution of such a complex and broad problem as ensuring the quality and safety of food products, the very objectification (formalization) of this problem in the legal sense is extremely important. First of all, this implies its registration in legal acts as a task, the solution of which should be directed at the activities of state bodies. In this regard, the status of a legal act is important (it determines the level of tasks and their importance for society), its industry affiliation, the clarity of the normative wording of the definitions used, the presence or absence of specific ways to solve the problem. The spectrum of legal means used to solve it, the activity of legislative and law enforcement bodies, and much more depend on this. However, from the point of view of the interests of national security, the legal formalization of the problem of quality and safety of food products does not, in our opinion, look quite definite.

Currently, ensuring the quality and safety of food products is positioned by the Russian legislator as an intersectional problem, the solution of which is carried out through the use of public law and private law mechanisms. This allows us to talk about the rules that establish various types of legal liability for violations in this area: administrative, civil, criminal. Moreover, among the problems of national security, this problem in the right sense has no independent significance, which, in our opinion, does not contribute to its resolution, interfering with the necessary concentration of organizational and legal efforts.

Indeed, in the fundamental strategic planning documents on safety, the need to ensure the quality and safety of food is considered as part of more general tasks. Such tasks, for example, are to strengthen public health and ensure stable demographic development of the country, which are recognized as Russia's national interests in the National Security Strategy of the Russian Federation [11]. In turn, the need to ensure these national interests made it possible to determine specific strategic national priorities of the Russian Federation, the implementation of which entailed the development of national projects, and the improvement of the legislative system in these areas. At the same time, it seems obvious to us that such national projects as «Healthcare»[12] and «Demography»[13] cannot be fully implemented without solving the quality and safety of food products. Thus, this problem should be solved within the framework of an independent direction of state activity, which, due to its enormous importance, should be given the status of a strategic national priority in order to ensure the national security of our country.

Of course, the legal «status» of a particular problem does not solve anything by itself. However, the assignment of the task of ensuring the quality and safety of food products to the «most important direction of ensuring national security» (which makes sense of the concept of «strategic national priority») allows you to localize this problem, highlight its subject field for «targeted» organizational, technical and legal impact, and accordingly, solve it. We repeat once again - the problem of quality and safety of food products is a separate factor of national security, which has independent significance in a complex of other problems. Moreover, the solution to the problem of quality and safety of food products is a prerequisite for the solution of those that are designated at the state level as long-term national interests.

At the same time, the leadership of the Russian state is stubbornly striving to solve this problem during and within the framework of solving other issues of national security. In the Russian language there is an expression - «in the course of the play», meaning any actions (most often unplanned) that are taken as a specific situation develops (as circumstances arise). This expression, in our opinion, best describes the modern approach of the Russian state to solving the problems of quality and safety of food products. As a result, government actions in this area are not systemic in nature; they are «eroded» in attempts to solve more global tasks, such as improving the quality of life, ensuring food security and others. Moreover, in a number of documents the very task of ensuring the quality and safety of food products is considered in a very truncated version, for example, in the National Security Strategy we have already mentioned, which, 
The Quality Improvement Strategy, as well as the National Security Strategy, considers the quality of food products as the most important component of the implementation of such national interests as improving health, improving quality and increasing the life expectancy of the population. Moreover, in the recent history of Russia, the Quality Improvement Strategy is the first strategic planning document that proclaims the quality of food products as its main goal.

It is noteworthy that among the tasks aimed at achieving the goals of the Strategy, the first is the task of improving and developing the regulatory framework, which indicates that the legislator is aware of the paramount role of organizational and legal mechanisms in ensuring the quality of food products.

Of interest is the paragraph in the text of the Strategy for Improving Food Quality from the General Provisions section, which, in our opinion, explains the reasons for the existing imperfection and whitespace of Russian legislation in the field of ensuring the quality and safety of food products. The creators of the Quality Improvement Strategy associate these reasons with the need to follow international standards and obligations of the Russian Federation as a member of the WTO and the Eurasian Economic Union, which was indeed the determining factor in the development of this block of Russian legislation at the previous stage.

A fundamental innovation contained in the Quality Improvement Strategy is the declaration of the need to establish mandatory requirements for the quality of food products. Prior to this, only safety requirements were mandatory in the sphere of food production and turnover. As we think, in this regard, making binding the requirements for product quality, we think, harmonizes these requirements with each other and helps to improve the organizational and legal mechanism in this area of relations.

In our opinion, the conceptual apparatus used in the Strategy for Improving Quality also serves the interests of harmonizing requirements in the field of quality and safety of food products. In particular, the definition of the quality of food products sounds like a set of characteristics of food products that meet the stated requirements and include its safety, consumer properties, energy and nutritional value, authenticity, the ability to meet human needs for food under normal conditions of use in order to ensure the preservation of human health [15]. As can be noted, in this definition, product safety is a characteristic included in the concept of product quality, which changes the approach to the correlation of these concepts in the future mechanism of legal regulation of this sphere of relations. The concepts of quality and safety become equal characteristics of food products from the point of view of their obligation, and accordingly from the point of view of ensuring the interests of citizens in improving the quality of life and maintaining their health.

The innovations indicated by us, as well as declarative provisions on the need to introduce food quality indicators into technical regulations for its individual types, the introduction of food grade and other gradations of its quality should be recognized as unconditionally positive. At the same time, the Quality Improvement Strategy envisages legal regulation of food quality issues within the framework of technical 
guarantee public interests in the field of food consumption (in other words, guarantee the population high-quality and safe food). Technical regulations for food products govern exclusively its safety issues, since only requirements for product safety are enshrined in Russian law as mandatory. Questions of the quality of food products remain at the discretion of the manufacturer, which creates conditions for the emergence of threats to the health and quality of life of Russians. Given the fact that the health and quality of life of the population are the subject of the national interests of the Russian Federation, it can be concluded that the imperfection of the Russian legislator in the field of ensuring the quality and safety of food products creates the possibility of harming the national security of our country;

- The interests of the sustainable development of our society require improving the organizational and legal mechanisms to ensure the quality and safety of food products. In our opinion, this is possible on the way to harmonizing the requirements for the quality and safety of food products, which implies a change in the current system of technical regulation based on the primary guarantee of product safety indicators to the detriment of its quality.

As an attempt to initiate the process of forming a new system of legal regulation in this area, one should consider the adoption by the Russian state of a Strategy for improving the quality of food products in the Russian Federation until 2030. This document declares the task of establishing mandatory requirements for the quality of food products. At the same time, the creators of the Strategy intend to implement legal regulation of quality issues within the framework of the current system of technical regulation, which raises reasonable questions regarding the possibility of such an option. The fact is that neither the Russian legislation on technical regulation, nor the regulatory documents of the Eurasian Economic Union, in accordance with the law of which we have technical regulation, do not contain norms that establish mandatory requirements for the quality of food products. Thus, it is impossible to carry out legal regulation of food quality issues within the framework of the technical regulation system without a fundamental change in the technical regulation system itself. And this is a difficult task, requiring the modernization of a number of regulatory acts, and not only domestic ones. However, we have no other choice.

\section{ACKNOWLEDGMENT}

«The reported study was funded by RFBR according to the research project №19-011-00926\19»».

\section{REFERENCES}

[1] M. T. Nurgalieva, A. K.Smagulov, and J. A. Iskakova, "Issues of regulating the quality and safety of food products in the framework of the European and Eurasian Economic Union", Science and World, 2016, vol. 1, no. 3 (31), pp. 86-91. 
14-14-14-53\&id=43:2011-09-01-16-46-34 \&option = com_content \& view $=$ article.

[11] "On the National Security Strategy of the Russian Federation", Decree of the President of the Russian Federation dated December 31, 2015 , no. 683, Collection of legislation of the Russian Federation, no. 1 (part II), 2016, art. 212.

[12] Passport of the national project "Healthcare", approved by the Presidium of the Presidential Council for Strategic Development and National Projects, Minutes dated 24 December, 2018, no. 16 [Electronic resource]. Available at: http://www.consultant.ru.

[13] Passport of the national project "Demography", approved by the Presidium of the Presidential Council for Strategic Development and National Projects, minutes of 24 December, 2018, no. 16 [Electronic resource]. Available at: http://www.consultant.ru.

[14] "On the approval of the Doctrine of Food Security of the Russian Federation", Decree of the President of the Russian Federation of January 30, 2010, no. 120, Collection of legislation of the Russian Federation, 2010, no. 5, art. 502.

[15] "On approval of the Strategy for improving the quality of food products in the Russian Federation until 2030", Order of the Government of the Russian Federation of June 29, 2016, no. 1364-r, Meeting of the legislation of the Russian Federation, 2016, no. 28, art. 4758.

[16] "On Technical Regulation", Federal Law of December 27, 2002, no. 184-FZ, as amended on 28 November, 2018, Collected Legislation of the Russian Federation, 2002, no. 52 (part 1), art. 5140.

[17] "On the quality and safety of food products", Federal law dated 02.01.2000, no. 29-FZ, as amended on 23 April, 2018, Collection of legislation of the Russian Federation, 2000, no. 2, art. 150. 